\title{
Information Systems for Large-Scale Event Management: A Case Study
}

\author{
Boon-Yuen Ng \\ National University of Singapore \\ ngby@alumni.nus.edu.sg \\ Atreyi Kankanhalli \\ Department of Information Systems \\ National University of Singapore \\ atreyi@comp.nus.edu.sg
}

\begin{abstract}
Information systems (IS) have considerable use in supporting large-scale communication and coordination. This is especially important in contexts such as major event and crisis management which have complex requirements on people and technology. IS facilitate the dissemination of real-time information and coordination among decision makers, and thereby the management of the entire event. This paper describes a case of management and deployment of IS for a large-scale event as an exemplar in this area. Singapore won the bid to host a major international event, the Annual Meetings of the International Monetary Fund and World Bank, collectively known as S2006. However, there were complex requirements and daunting challenges to be overcome in managing such a high-profile and large-scale event. The paper describes how the Committee in charge delivered the IT infrastructure and systems for this large-scale event with 23,700 participants from 184 countries. It suggests several lessons for IT executives in charge of managing large-scale events, mainly for planned (e.g., sports events) and to some extent for unplanned (e.g., Japan tsunami or BP oil spill crisis) events. Particularly, it highlights the need for advance preparedness, use of IS for situation awareness, cultivating relationships for communication and coordination, and the importance of vendor management and project management skills. These lessons are valuable for IS deployment for large-scale communication and coordination for future mega-events and to some degree for preparedness for unforeseen events.
\end{abstract}

Keywords: Large-scale communication and coordination, Event/conference management, Planning and preparedness, Situation awareness, IT project management, Crisis management 


\section{Introduction and Background}

Large-scale communication and coordination are necessary in various critical situations such as military operations, healthcare epidemics, disaster management, and major event management which have complex logistics requirements. This research area has gained interest in recent years (Ritter et al., 2007), with new challenges continuously appearing such as the Japan Tsunami. Largescale event management involves managing interdependent tasks among multiple parties for which effective communication is a key pre-requisite. Such communication and coordination are required both for planned events (e.g., international conventions and sporting events such as the Olympics and World Cup) as well as in response to unplanned events (e.g., disasters such as hurricanes or the recent Gulf oil spill).

However, while the use of information systems (IS) is ubiquitous in practically all sectors of the economy, one of the lesser studied sectors in which ICT plays both strategic and operational roles is the events, conventions, and meetings industry. This industry deserves more attention as it can contribute substantially to regional and national economies and stimulate the growth of tourism activities (Lee and Back, 2005). According to a recent market study, the meetings industry in the U.S. directly contributed $\$ 106$ billion to the GDP in 2009 and supported nearly 1.7 million jobs (Kovaleski, 2011). In fact, this ranks higher than other key industries such as automotive manufacturing and air transportation.

IS have considerable potential in supporting communication and coordination for largescale event management. IS facilitate the dissemination of real-time information among multiple stakeholders and provide various collaboration technologies and tools. Largescale event management often requires individuals to act decisively and quickly based on information from multiple parties. Thus, sharing and dissemination of information is critical for which IS are indispensable (Manoj and Baker, 2007). For instance for the 2010 Fifa
World Cup tournament, an innovative event management system was developed to provide a seamless experience for all fans, delegates, and staff members, and to manage assets (The Economic Times, 2010).

IS also play an important role in unplanned events such as crises. For example, information technology can be strategically used to coordinate rescue efforts during disasters or even to combat health crises such as the SARS outbreak in 2002 (Pan et al., 2005). In the recent Gulf oil spill, IS were used to inform and forecast the spread of the spill. For example, Thomson Reuters used IS to monitor toxic exposures and keep the Center for Disease Control (CDC) and poison control centers updated (Thomson Reuters, 2010). Crowd sourcing through the Internet was deployed to compile information concerning the disaster while social networking sites allowed the public to suggest and vote on ideas to stop the oil spill (Hart, 2010).

The key to using IS for large-scale event and crisis management lies in being prepared (Junglas and Ives, 2007). IS have to be specifically planned and developed for largescale communication and coordination, as such systems cannot be built overnight when required. Instead, governments and firms have to deliberately and purposefully develop their capabilities, so that such IS can be leveraged at times of needs, whether for planned or unplanned events. Coordination for large-scale events, such as disasters, is challenging due to the complex and changing requirements and limited response time (Chen et al., 2007). While IS have the potential to improve information quality and support decision-making during large-scale event management, there is a lack of research and understanding about the development and use of such systems (e.g., Chen et al., 2007, Reddy et al., 2009). Thus studies on the successful deployment of IS for large-scale communication and coordination can help to address this knowledge gap.

This paper describes the way in which IS were effectively deployed for management and delivery of a large-scale international 
event. The Annual Meetings of the Boards of Governors of the International Monetary Fund (IMF) and World Bank (WB) was held in Singapore and also known as S2006. The Annual Meetings are the world's largest and most comprehensive gathering of global financial representatives. These meetings are held outside Washington D.C. once every three years. Along with the Annual Meetings, a series of over 300 international meetings and seminars had to be hosted in Singapore, including the G-7 Finance Ministers' Meeting, the Program of Seminars and the Group of Thirty International Banking Seminar. Overall, S2006 was one of the largest international events ever to be hosted in Singapore. There were 23,700 participants, including heads of government, finance ministers, central bank governors, and other delegates from 184 countries.

The requirements for information technology for the event included providing continuous and seamless connectivity and computer security for the large number of participants. For the organizers, IS were required for facilitating round the clock situation awareness and preparedness. Although Singapore has been known for its IT infrastructure and strategy (World Economic Forum, 2010-11), meeting the requirements for the event was challenging. The S2006 project was characterized by the high visibility and large scale of the event. As this was a critical event to be attended by high-profile delegates from all over the world, it was imperative for the IS requirements to be met so that the Annual Meetings could proceed smoothly. The IT infrastructure had to be robust and able to handle the required load. Performance and availability of IT services had to be guaranteed at all times. Security had to be enforced round the clock to protect sensitive data and systems. The schedule of the event was non-negotiable, hence all planning, preparation and deployment work had to be completed on time.

With the large number of participants, meetings, and other related events, Singapore International Convention and Exhibition Centre (Suntec) was chosen as the appropriate venue for S2006. Suntec is a renowned, interna- tional venue for meetings, conventions and exhibitions. Within the venue, more than 1000 temporary offices had to be set up for the delegates' use during the event. Since Suntec is rented out continuously for different activities, the IT infrastructure for the temporary offices had to be swiftly set up and torn down after the event. Thus, IS had to developed and deployed for ensuring connectivity, situation awareness, security protection during the event period, and coordination between public and private sector organizations and event participants. This was the daunting task facing the Chairman and the Communications Infrastructure sub-committee (referred to as the $\mathrm{Cl}$ from now on) of the S2006 Organizing Committee.

Overall, with the lack of research and understanding of effective IS deployment for largescale event management, this case study aims to answer the research question: How could IT infrastructure and IS applications be successfully planned, implemented, and delivered to meet the requirements for such events? Accordingly, we begin with a brief review of the literature on IS development and deployment. This is followed by the research methodology, case description and findings in each phase of the IS project studied. The findings are described in terms of the project requirements and phases. For each phase, we describe the activities and IT support, issues involved in matching IT to the task requirements, and the IT solutions derived. Finally, we describe the lessons learnt from this case and derive a framework of IS for large-scale event management. We also discuss how the lessons may be useful to some extent for unplanned situations, such as crisis management and disaster recovery. This is because while planned events such as the S2006 differ from unplanned events such as natural disasters in terms of flexibility for unanticipated requirements, public response management, and consequences, both kinds of events require continuous awareness, swift communication and coordination, and management of security threats, all of which are enabled through the use of IS. 


\section{Literature Review}

While there is limited literature on IS for event management (Rai and Sambamurthy, 2006), considerable research has been conducted on IS development and deployment in general and in other contexts, which may be partly useful for our study on event management. A recent study by McLeod and MacDonell (2011) has reviewed the IS project literature and developed an updated and comprehensive classification framework for the factors that influence IS project outcomes. These factors are grouped into four categories i.e., people and action, development processes, project content, and institutional context. Below, we discuss each category and the themes under it that may be relevant to IS for large-scale event management.

\section{People and Action}

Several key stakeholders have been defined for IS projects e.g., developers, project manager, users, and external agents (e.g., vendors or clients). A group of these actors constitute the project team that is responsible for the IS development and deployment. Past research has identified two important attributes of team members for the success of a project, i.e., experience of the developers and knowledge of users (Kirsch, 2000). While technical and business experience are important for the project team, soft competencies could be critical for managing relationships in large projects (Dillon et al., 2011).

Previous research has also identified various competencies for IT project managers i.e., team leadership, planning and control, relationship building, achievement and client orientation, problem solving, interpersonal and team development skills (Napier et al., 2009). With the increasing level of complexity, particularly in large-scale projects with multiple stakeholders, it is important to understand how project managers should be equipped to deal with such dynamics (Thomas and Mengel, 2008).

External relationships refer to the linkages with external constituents such as vendors and clients. The nature of the IS-client rela- tionship can affect project outcomes. The relationship may vary from being arduous to trustful (Ko et al., 2005), which can affect how conflicts are resolved. Specifically, conflicting assumptions and expectations may affect the understanding of requirements, system design, and eventually the project outcome (Ovaska et al., 2005). Social interdependencies between IS developers and clients can also influence the extent of knowledge sharing between them and resultant project performance (Pee et al., 2010). At the same time, today's dynamic business environment requires IT projects to source from multiple vendors and manage complex relationships with them as well (Levina and Su, 2008). It is thus important to understand how communication and external relationships can be fostered for large-scale IS projects such as the S2006 event under study.

\section{Development Processes}

Aspects of systems development processes are likely to influence IS project outcomes. The key processes include requirements determination, project management, user participation, and user training (McLeod and MacDonell, 2011). Requirements determination involves gathering and analysis of requirements, typically from end-users, followed by system design based on the requirements. It is aimed at achieving a shared understanding of the information, processes and functions that need to be incorporated into the new system. Ambiguous, changing, incomplete, or misunderstood requirements are a major concern in large-scale IS development projects, which may lead to failures if not managed adequately (Hartman and Ashrafi, 2002).

Project management concerns planning, organizing, and managing resources (human, financial, and technical) throughout the duration of the IS project to achieve its objectives. Planning activities include defining the project, estimating its size, cost, and schedule, assessing the risk, and developing a project plan. These activities are usually undertaken by a project manager or a committee in the case of large and complex projects. Project management techniques and models are 
considered particularly relevant for these projects (Gowan and Mathieu 2005) and have also been recommended for event management as they provide guidance for tackling various challenges involved (Shone and Parry, 2010).

User participation and training refer to activities performed by users in defining and testing the system followed by their training to successfully use the system. Previous research has shown that participation from users is an important factor for the success of IS planning and development ( $\mathrm{He}$ and King, 2008). User acceptance is facilitated by their participation in the project right from the early stages of development. Participation also results in greater ownership of the IS project and a better match between user expectations and the delivered system (Irani et al., 2001). This is of particular concern in large and complex IS projects with multiple groups of often heterogeneous users. User training is also considered to impact project outcomes through influencing user attitudes towards the system (Skok and Legge, 2002). Training is most effective when users gain skills and experience in using the system thereby building their confidence, knowledge, and acceptance of the IS. Since user training can be arduous for large and complex IS with multiple user groups that perform interdependent work using the system, additional research would be useful for identifying training strategies for such contexts.

\section{Project Content}

This category includes IS project characteristics, resources, and technology supporting system development and deployment (McLeod and MacDonell, 2011). Project characteristics such as size and complexity have been seen to affect IS project outcomes (Johnson et al., 2001; Kautz et al., 2004). Large projects are more likely to have high complexity, task interdependence, need revision, require more resources and communication, and have more potential for conflict. Additionally, IS project complexity arises out of increasing functionality, scope and speed of technical change, and the need for system integration. Both characteristics are manifest in the large-scale project under study, which requires further research to elucidate the best practices of managing such projects.

Further, the level of resources (financial, human, and technical) available to the IS project are central to its outcomes. The allocation of adequate resources to a project can indicate top management support (Kearns, 2006), whereas the lack of resources can result in the project being stalled (Lederer and Sethi, 2003). For large-scale systems, both top management support (Biehl, 2007) and sufficient resource allocation (Bechor et al., 2010) are considered as critical success factors. At the same time, resource allocation and management becomes complex when multiple stakeholders are involved, requiring further research in this area.

There are various issues related to the technology for supporting IS development, which impact project outcomes. Specifically, selection and use of inappropriate technology, rapid changes in technology and infrastructure, as well as inadequate technical resources can adversely affect the IS project (Kim and Peterson, 2003). For large-scale and complex IS projects, customized tools and techniques for project management and monitoring may need to be developed since existing methods may not sufficient. However, new or unproven tools introduce risk in the IS development that requires additional planning to alleviate. Thus, further research is needed to elucidate how appropriate technologies can be developed and deployed to support the management of such projects.

\section{Institutional Context}

The fourth category of factors relates to the organizational characteristics and environmental conditions for IS project success. The organizational attributes include culture, policies and practices, the history of systems development and use, and the legacy systems and infrastructure (McLeod and MacDonell, 2011). Since large-scale projects such as the one under study involve multiple agencies and external partners, the diversity of organizational cultures and policies may impact the 
IS project development and implementation. At the same time, the legacy systems available in each participating organization might influence how the new IS project is envisioned. The IS project under study thus provides an opportunity to examine how diverse organizational culture, practices, and systems can be brought together for a common objective. The environmental conditions include the socio-political, economic, and national context for the IS project. Since, the project under study was a government-organized event of importance to the whole country, various national considerations may determine the project objectives and requirements.

Based on the above literature review and themes, we analyzed the current case with the possibility of adding to and revising the existing themes according to the case findings.

\section{Research Methodology}

A qualitative case study approach was adopted to analyze the S2006 project to answer our research question on how IT infrastructure and IS applications could be successfully implemented and delivered for large-scale event management. The case study approach provides richness of data and allows researchers to study the use of IS in a natural setting (Walsham, 2006). Moreover, S2006 was a rare and important event, thus making this case unique and revelatory (Yin, 2008). This method is therefore a suitable choice for studying the implementation and use of IS for management of such a largescale event. This study adopts the interpretive approach where theory is not being tested. The focus is to understand the context of how IS are used and the process whereby the systems interact with the context (Klein and Myers, 1999).

\section{Case Background}

The planning and preparation of this event would end up taking four years and mobilizing 8000 employees from various government agencies, 4000 volunteers, and 800 military personnel. All kinds of requirements had to be carefully planned for, such as the accom- modation of delegates, the logistics of the many meetings, the security of the participants and information, and the connectivity required for this event.

The making of S2006 required close collaboration and partnership between the government and the Joint Secretariat of IMF and WB (referred to as the JS from now on). It also necessitated coordination among the various government agencies. Further, it required collaboration and partnership between the government and the private sector. Thus, an additional challenge was managing multiple stakeholders and their changing requirements.

The S2006 Steering Committee consisted of Permanent Secretaries (senior-most officials) from various government agencies. Under its guidance, the inter-agency Organizing Committee was formed for the planning and coordination of this event. The Organizing Committee further set up ten sub-committees to be in charge of different areas (see Appendix $A$ for the details of the sub-committees of the Organizing Committee). The $\mathrm{Cl}$ was a subcommittee that was responsible for all the IS functions for the event. Its members came from the Infocomm Development Authority of Singapore (IDA) ${ }^{1}$, which is a government agency serving the roles of infocomm industry champion, national infocomm master planner and developer, and Government $\mathrm{ClO}$.

The $\mathrm{Cl}$ had to plan, oversee, manage and coordinate the deployment of communications infrastructure, such as telecommunication systems and IS applications for the event. These systems had to meet the requirements of the JS and the Organizing Committee. The goal was to ensure the highest standards of communications infrastructure support and services throughout the event. The areas under the purview of the CI were: (1) IS applications; (2) Desktop environment and helpdesk services; (3) Tele-communication and postal services; (4) Network infrastructure; and (5) Server hosting facilities and services, and electrical power support system.

\footnotetext{
1 The authors would like to thank the Infocomm Development Authority of Singapore for research access.
} 


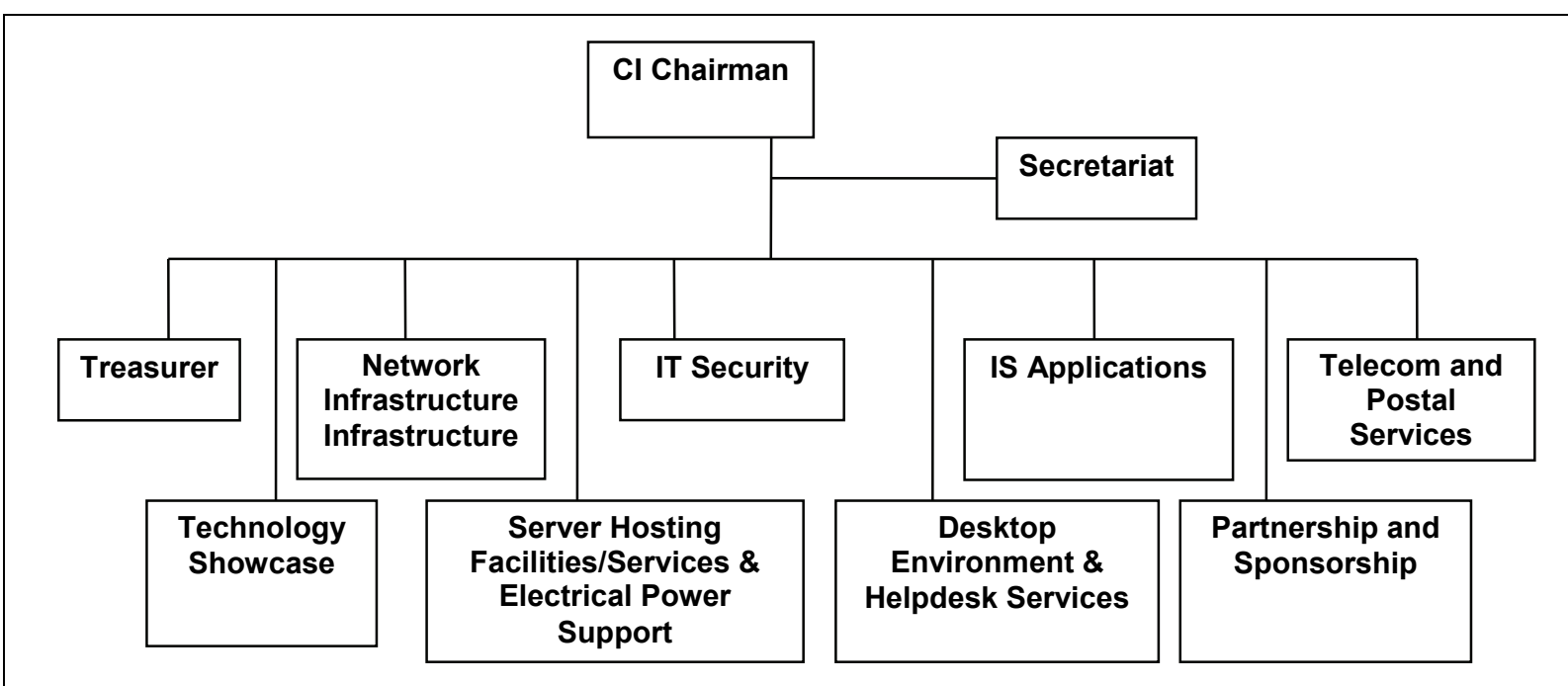

Figure 1 - Organization Structure of the $\mathrm{CI}$

To serve the different areas, the $\mathrm{Cl}$ set up the organization structure as shown in Figure 1. There were altogether nine teams, led by team leaders. Each team consisted of two or three members. Apart from the five areas listed in the previous paragraph that the $\mathrm{Cl}$ was in charge of, there were four additional teams: (1) Treasurer to take care of financial matters; (2) IT Security to ensure the security of the IT infrastructure and applications; (3) Technology Showcase to prepare an IT showcase for the delegates; and (4) Partnership and Sponsorship to liaise with partners and sponsors from the private sector.

\section{Data Collection and Analysis}

Multiple data collection methods were used for this study (Klein and Myers, 1999). 11 semi-structured interviews were conducted with all key members of the $\mathrm{Cl}$ after the event. The interviewees included the $\mathrm{Cl}$ Chairman, the $\mathrm{Cl}$ secretariat, and team leaders in charge of various areas such as network infrastructure, server hosting facilities, IS applications and helpdesk services (refer to Figure 1). Interview questions are developed based on the timeline and activities/phases of S2006. The interview protocol is provided in Appen$\operatorname{dix} B$. The interviews were on the average one and one-half hours in duration. All interviews were transcribed and analyzed. Additionally, large amounts of secondary data were collected from the different stakeholders including publicity materials and key project documents. Other secondary data came from media coverage as well as press releases on the Internet. Cumulatively, these data were analyzed to create a detailed history of the event and the phases, as well as to identify key lessons from this case.

As the focus of this study is not on theory generation or testing, we used a "looser approach" (Walsham, 2006, p.325) for interpretive research. Though the variables were not predefined, our analysis was guided by the themes derived from our literature review of IT project management literature with the allowance for identifying additional themes and concepts. Impressions and notes were written down after each interview to generate a more organized set of themes. We chose to focus on issues and challenges encountered by the S2006 team and how these challenges were overcome. In addition to organizing data based on issues, data was also coded based on the phases of project management, i.e., planning, preparation, and execution (Project Management Institute, 2008).

The rest of this paper describes the IS requirements and challenges for S2006, the IT activities and support, and how the requirements are matched with the activities. We begin by describing the IS requirements, fol- 
lowed by the three main phases of the project, i.e., planning, preparation and execution. The planning phase describes the gathering of IS requirements, whereas the preparation and execution phase describe the corresponding challenges and their solutions, and how the requirements are matched with the activities. Finally, the paper discusses the lessons that were derived from the project and develops a framework that integrates these lessons.

\section{Requirements for IS}

Through our coding and analysis of interview data, we derived the three main IS requirements for the $\$ 2006$ project, i.e., staying connected, situation awareness, and security at all times.

\section{Staying Connected}

Information technology was a necessity for participants to stay connected globally, be it through computer Internet access, or through the use of mobile phones. As the delegates were from 184 different countries and different time-zones, it was important to provide connectivity at all times so that participants could communicate amongst themselves as well as with their home countries. Besides basic network connectivity, the JS also requested that delegates should be provided the means to send and receive internal messages among themselves. The $\mathrm{Cl}$ also looked into the option of providing wireless access as a value-added service for the delegates. The purpose was to provide seamless connectivity to the Internet, anytime and anywhere in the vicinity of the meeting venues. The Deputy Chief Executive of IDA and Director-General (Telecoms) commented in a media release:

Having a well-connected and seamless Infocomm infrastructure in place is integral for the operation of such a large scale international event.

The $\mathrm{Cl}$ also aimed to provide delegates with various informational services, such as news updates and weather alerts. Such services harnessed the connectivity provided by the IT infrastructure so that delegates could access the latest information at all times. Last, a business center was required to provide telecommunications and postal services for the delegates. Services needed included telecommunication, postal, courier, broadband services and rental of communications equipment and lines.

There were several challenges involved in meeting these requirements. First, the large scale and complexity of the event required a substantial amount of IT equipment, such as routers and computers. However, these equipments would only be used for a short span of time during the Annual Meetings. Purchasing the equipment required significant funds and the disposal of the assets after the event would be problematic. Second, as the event would be held in rented premises and temporary offices, the set-up and tear-down of the IT infrastructure must be done quickly within the rental period. This implies that the $\mathrm{Cl}$ had to deploy a large number of personnel to complete the tasks speedily. These were some of the issues that the $\mathrm{Cl}$ Chairman had to grapple with while deciding how to meet the key requirement of providing IS for keeping participants connected.

\section{Situation Awareness}

In order to manage hundreds of meetings attended by tens of thousands of participants, the $\mathrm{Cl}$ was faced with a daunting task, i.e., to monitor the events (including information pertaining to meetings, venues and participants) and be kept updated on all situations in realtime. In the initial planning days, the team conceptualized a system that would track only exceptional incidents, but subsequently it became clear that the system must aid in maintaining situation awareness at all times. As explained by the $\mathrm{Cl}$ Chairman:

A control and command system was not in our agenda [initially]. It was more like an event monitoring system. Then, one year before the event started... [we] turned this event monitoring timetable system into a command and control system... for the better management of the whole event.

To satisfy this objective, the $\mathrm{Cl}$ team realized that existing systems would not be adequate. 
A new application would have to be designed to meet the requirements of capturing incident/situation and status of events and venues, indicating the level of attention required for each incident/situation using color codes, sending notifications to users of the systems, interfacing with handheld communication devices, integrating with another application (a Personnel Record System) that contained delegates' information, and generating status reports.

With the non-negotiable deadline, the $\mathrm{Cl}$ faced a demanding task to design and develop such a complex application. As the users of this new application came from different government agencies and subcommittees, it was a challenge to gather and meet the requirements from the diverse users and to ensure the effective deployment of the system among them.

\section{Security at All Times}

Past IMF/WB events witnessed protests by anti-globalization activists attempting to spread their ideology through various tactics ranging from physical blockage of the event venue to cyber attacks. Activists could attempt to create cyber disruptions by targeting Singapore government's web presence in order to discredit the event and embarrass the organizing country. In view of this risk, one of the requirements for the $\mathrm{Cl}$ was to set up a computer security monitoring service for the IS applications and the event website. This was to ensure that any computer threat to these systems was quickly identified and addressed. The onus was on the $\mathrm{Cl}$ to ensure the smooth and secure operation of all IT infrastructure and services at all times, without any compromise to the confidentiality, integrity, and availability of the systems and data.

\section{Planning Phase: Gathering Re- quirements}

Four years before Singapore hosted the Annual Meetings, the Organizing Committee was officially set up, represented by various government agencies which were in charge of different areas. At the same time, the $\mathrm{Cl}$ and the other sub-committees were also formed. Subsequently, $\mathrm{Cl}$ members had to be reshuffled as some of the members at that point of time were working in different locations in Singapore with other commitments. The Chairman of the $\mathrm{Cl}$ saw the need to fill the positions with members who were based at the IDA Headquarters with commitments only to the Headquarters, so as to facilitate meetings and to have more control over manpower resources.

The major task for the $\mathrm{Cl}$ during this phase was the gathering of requirements for IT infrastructure and applications. This was done in various ways. First, representatives from the $\mathrm{Cl}$ visited the Annual Meetings held in Dubai and Washington D.C., to obtain firsthand experience on how the events were conducted. Second, the JS also furnished the $\mathrm{Cl}$ with their IS requirements based on what was used in the previous event. Subsequently, an updated version of the requirements was provided, with adjustments based on how technologies had changed. Third, requirements were gathered from the other agencies in the Organizing Committee.

In response to the requirements from the different sources, the $\mathrm{Cl}$ identified the need to develop the following IS applications: (1) Organizing Committee Tracking and Update System (OCTUS) which was required for event monitoring and situation awareness; (2) Personnel Record System (PRS) which was needed to manage the personnel information of the delegates and would be integrated with OCTUS; (3) S2006 Email System (SES) which was based on a requirement from the JS to facilitate the sending of internal messages among delegates during the event; and (4) Web-based Repository System (WBRS) which was to facilitate the sharing of documents among the Singapore government agencies. The WBRS was implemented and extensively used by all sub-committees to share documents during the planning and preparation phases.

The $\mathrm{Cl}$ conducted preliminary sessions with the various sub-committees to understand and document the user requirements for OCTUS and PRS during the planning stage. As 
IDA did not have the internal capabilities to develop the applications, the system development was to be outsourced to vendors. The plan was to call for tenders during the preparation phase for the development of OCTUS and PRS. Other requirements were gathered for the hosting environment for the servers. The $\mathrm{Cl}$ planned to call a tender to construct the server rooms and supply airconditioning, electrical and back-up power for the rooms. The conclusion of the planning phase was marked by the approval of the plans by the Organizing Committee. This phase revealed the initial IS requirements for the event. However, some of these requirements remained fluid throughout the preparation and even execution phases due to the dynamic nature of the event.

\section{Preparation Phase: Meeting Re- quirements}

The preparation phase was characterized by the calling of tenders to implement systems and to obtain IT equipment to meet the requirements. The main activities were the writing of tender specifications and evaluation of tenders. There were two key groups of users providing requirements for this event i.e., the JS and the Organizing Committee. The Organizing Committee's requirements came from the various sub-committees in order to support and provide the necessary IS services and equipment for their respective responsibilities.

\section{IT Infrastructure Provision}

For the IT equipment, the $\mathrm{Cl}$ had gathered responses from all agencies to find out their needs. This was done in several rounds, in which the agencies had to justify the necessity and use of the equipment. However, there was one major issue to be resolved, i.e., the disposal of the assets after using the equipment for the event. As a way out, the $\mathrm{Cl}$ Chairman requested the Organizing Committee to mandate that the agencies source the IT equipment they needed from within their own organizations. The $\mathrm{Cl}$ would only be responsible for providing IT equipment to be used by the JS and the delegates.
Although this mandate cut down requirements substantially, the amount of IT equipment necessary to meet the requirements of the JS and the delegates was still significant. The key concern was asset disposal and cost savings. Regular discussions and negotiations took place with the JS through video and phone conferencing during the preparation phase to minimize the requirements without affecting the JS's needs. Subsequently, the $\mathrm{Cl}$ partnered with various IT companies for sponsorship of equipment and services. For example, networking giant Cisco Systems was roped in to provide the network infrastructure for the delegates to stay connected. Also, 1020 analog and 1025 multi-line digital phones were provided by Alcatel and connected to Alcatel's digital PABX system.

For the remaining equipment, the $\mathrm{Cl}$ called for tenders. The leasing option was preferred as this avoided the asset disposal problem and provided better value-for-money. Also, some of the equipments were leased from within the government. For example, after discovering that one of the government agencies would be purchasing 1000 new personal computers for their own organization, the $\mathrm{Cl}$ arranged to lease the computers from them for S2006 to be returned in good condition after the event.

Although the $\mathrm{Cl}$ had gathered initial requirements from the JS and the other government agencies, the requirements changed frequently. In almost all cases, the requirements were increased. Changing requirements from multiple parties posed a major challenge to the $\mathrm{Cl}$. As a result, the $\mathrm{Cl}$ constantly renegotiated with the partners from the private sector to meet the increased requirements. Whenever there was an increase in requirements, the $\mathrm{Cl}$ again approached the private firms that were providing the equipment. As they were supplying their equipment and/or services out of good will rather than with payment, the $\mathrm{Cl}$ ensured cordial relationships with them. The Chairman of the $\mathrm{Cl}$ elaborated:

When we talked to the sponsors, it was a totally different ball game because it was really how much they were willing to help 
us. We cannot treat them like a vendor and go after them. We really need to be more diplomatic and it involves a lot of convincing.

The $\mathrm{Cl}$ also kept buffers or extra resources by asking for more than what was required. Thus, the $\mathrm{Cl}$ negotiated at one end and "buffered" at the other end for the equipment. All buffers were used up eventually as there were frequent increases of requirements. The $\mathrm{Cl}$ Chairman recounted this incident:

We said to our partner, for example, "We need $3003 G$ SIM cards. Is it possible for you to give them to me?" When they said yes, we went back to the government agency and said "Yes, we have met your requirement!" Then they said, "Is it possible to [increase] by another 100?"

Other tenders that were called for during this period included tenders for network cabling infrastructure, IT desktop equipments, setup and operational support for both network and desktop, telecommunications equipment, and construction of server rooms and provision of hosting services.

\section{IS Applications Design}

In response to the need for situation awareness, the $\mathrm{Cl}$ designed an IS application specifically for this event i.e., Organizing Committee Tracking and Update System (OCTUS). OCTUS was the first-of-its-kind tool used for event monitoring and situation awareness. One of the key requirements of OCTUS was that it should be able to interface with $3 G$ mobile phones so that information for the command center could be obtained through these phones. For example, when important delegates (such as governors and heads of central banks) arrived at the airport, they were each received by a liaison officer who used a $3 G$ phone to update the arrival and alert the hotel staff members to receive the delegate.

OCTUS also had to interface with the Personnel Record System (PRS) which contained information about the delegates, such as their registration details, arrival times and accommodation arrangements. This was an- other input to OCTUS which allowed the system to generate information such as estimated attendance of a specific event. Together, these information sources allowed OCTUS to provide complete situation awareness.

Tender specifications for the development of OCTUS and PRS were prepared, reviewed and approved. The major phases of system development were: (1) Detailed requirements gathering from users; (2) Development; (3) User acceptance testing; (4) User training; and (5) Implementation. The SES email system was also developed to be deployed in emessaging kiosks. Delegates were able to communicate with other participants using the SES through the kiosks.

With the increasing amount of information, complexity and coordination across agencies, the Web-based Repository System (WBRS) was now insufficient for coordination purposes. The Organizing Committee saw the need for an integrated project management tool to be used by all the agencies. The $\mathrm{Cl}$ thus purchased and deployed the Enterprise Project Management System (EPMS). Though the implementation of the EPMS was through a top-down mandate, the usage was not as high as expected. One possible reason was that the EPMS was introduced rather late, in the middle of the preparation phase. By this time, most users had already developed their own means of managing the project. A Cl user noted:

We tried to use the project management tool. It would have been useful if it was used. But it requires people to work differently from their usual way. We need a longer runway...the tool came in very late...it requires quite a bit of behavioral change. Even though I am IT-trained, I find it quite hard to make the change.

\section{Offering Value Added Services and Other Preparations}

Besides provisioning for the IT infrastructure and applications, preparations were also made to offer value-added services for the delegates. The $\mathrm{Cl}$ partnered with government 
agencies and the private sector, as described below.

One of the value-added services was the provision of wireless access for the delegates at Suntec and the shopping areas within walking distance from Suntec. This service gave delegates seamless connectivity to the Internet, anytime and anywhere in the vicinity of the meeting venues. This was made possible through a wireless broadband program initiated by IDA, called Wireless@SG. The Wireless@SG program is part of Singapore's nation-wide Next Generation National Infocomm Infrastructure initiative. Wireless@SG allowed users to enjoy free, both in-door and outdoor seamless wireless broadband access in most public areas. IDA saw the potential synergy in making Wireless@SG available first to the delegates and public visitors in the central shopping areas for the duration of the Annual Meetings. This was a lead-up to the commercial deployment of Wireless@SG after the event. It was a win-win situation as the delegates benefited from the wireless free service and experienced how Singapore leverages IT for productivity, while IDA used this platform as a preview for the full island-wide roll out, and as an opportunity to receive feedback from users to improve the service before its commercial deployment.

For other value-added services, the $\mathrm{Cl}$ worked with companies such as local carrier SingTel to provide US $\$ 1.3$ million worth of voice, mobile, data and broadband connectivity to participants. Various informational services, such as news updates, weather alerts and flight schedules were also made available to the delegates. Further, the $\mathrm{Cl}$ partnered with E-Cop to meet the high level of vigilance requirements and ensure $24 \times 7$ information security surveillance services for round-theclock proactive surveillance and protection of the OCTUS network and event website. The $\mathrm{Cl}$ also made preparations so that all details were taken care of and the event would run smoothly. Flowcharts for different scenarios and tasks were drawn up so that all procedures were clear to members and contingencies were planned for.
The $\mathrm{Cl}$ Chairman was also mindful of the team dynamics and cooperation within the $\mathrm{Cl}$. $\mathrm{He}$ was proactive in organizing team building exercises so that members could get to know each other well and learn how to co-operate. During these team building exercises, $\mathrm{Cl}$ members were honest in sharing their expectations as well as what they required from other teams in the $\mathrm{Cl}$ so as to improve their work procedures. The amicable relationships and the regular meetings within the $\mathrm{Cl}$ helped in their delivery of quality work. $\mathrm{A} \mathrm{Cl}$ member noted:

The team dynamics is quite good. We are all quite close to each other...Within the $\mathrm{Cl}$, we're pretty cohesive.

However, it was more challenging for the $\mathrm{Cl}$ to work with the Organizing Committee and the other sub-committees. A Cl member noted:

With a lot of different sub-committees, it is not easy to communicate. You don't know who is who, and people keep changing. Then later there was organizational change...it can be difficult.

\section{Execution Phase: Delivering Re- quirements}

The main tasks for the execution phase included delivering and setting up IT equipment, and deploying IS applications. The execution phase also included the monitoring and operations of the actual event.

\section{Delivering IT Infrastructure and Ser- vices}

More than 12,000 cabling points and over 40 wireless access points were set up, with more than $960 \mathrm{~km}$ worth of cables in use. More than 1000 delegates' offices as well as meeting rooms were equipped with high-speed local digital leased circuits, Internet broadband access, desktop computers, printers and telephones to facilitate communications and operations. Other equipment provided to the delegates for their connectivity included 1665 mobile phones, 1328 SIM cards, 710 printers and 80 barcode scanners. To allow delegates to send and receive internal messages 
among themselves, the $\mathrm{Cl}$ arranged for $30 \mathrm{e}$ messaging kiosks. The kiosks were also one of the means by which delegates could access the Internet.

One of the major challenges was the short amount of time given to set up the IT infrastructure. This task had to be closely coordinated with the vendors in charge of constructing more than 1000 temporary offices. The laying of network cabling points had to coincide with the construction of offices and the IT equipment could only be deployed after the temporary offices were ready. The vendor was given only 12 days to install the 12,000 network points. After the network infrastructure was set up, the vendor, together with the $\mathrm{Cl}$ and the internet service provider, conducted tests on the resiliency of the network before the system was commissioned for full deployment. Following the deployment, the vendor had to setup and configure the personal computers according to the requirements from the JS and ensure all equipment was in working condition. Upon completion of the deployment, an inventory list was prepared detailing the equipment that was set up in each room or area.

A business center was also set up to provide telecommunications and postal services for the delegates. Some of these services and equipment were made available through partnership with Singapore Telecommunications, Singapore Post, DHL and United Parcel Service. The $\mathrm{Cl}$ gave the mobile phones and SIM cards to the JS representative who was in charge of distributing them to the internal JS staff members and collecting and returning the equipment to the $\mathrm{Cl}$ after the conclusion of the Annual Meetings. Even during this period, right up to the eve of the event, there were changing requirements from the JS. Negotiations were still being conducted with the JS due to the last-minute changes. The $\mathrm{Cl}$ also worked quickly with the vendors and partners in providing the infrastructure and services to meet these requirements. By this time, the value-added services, such as wireless access and informational services, were also ready to be used by the delegates.

\section{Deploying IS Applications and Scenar- io Exercises}

Training sessions for OCTUS were held after the system was commissioned and deployed. Due to the large number of personnel who would be using OCTUS, mass training sessions and train-the-trainer sessions were conducted, with one-to-one help given after the training sessions for those who needed more assistance. OCTUS was also used during the scenario exercises described below, giving staff members the opportunity to practice using the system before the actual event. The Personnel Record System PRS was also deployed prior to the event. The system was populated with personnel data. Further, the SES email system was ready to be deployed on the e-messaging kiosks. Volunteers were trained to assist delegates who needed help with SES or the e-kiosks.

A key requirement related to OCTUS was ensuring smooth and secure operations at all times during the event. One of the highlights of the execution phase was conducting scenario exercises to prepare for contingencies. Scenario exercises are tools to draw participants into a convincing portrayal of a plausible reality (Goles et al., 2005) and test the response of participants. These were organized by the Crisis and Contingency Workgroup which was part of the Organizing Committee. There were a number of scenario exercises, ranging from table top exercises where the scenarios were played through in a room to full-troop exercises where participants reacted and responded to simulated scenarios. Although the $\mathrm{Cl}$ Chairman needed to assign only key representatives to participate, he made a decision for all members of the $\mathrm{Cl}$ to participate in the scenario exercises, so that everyone was trained and fully prepared for all kinds of scenarios. The scenarios were decided by the workgroup, together with key representatives from each subcommittee. Examples of the scenarios for the $\mathrm{Cl}$ included virus attacks on systems, slowness of network, and break down of emessaging kiosks. 
Through the scenario exercises, a few objectives were achieved. People knew how they should respond and who they should call should incidents occur. The communications functions were thus tested. OCTUS was also used by the participants to log incidents and update the command centre. Through the exercises, participants became familiar with the use of OCTUS, so that they would not fumble if they had to log or update an incident during the event. The scenario exercises also helped the $\mathrm{Cl}$ to get to know people in other sub-committees. One of the participants from the $\mathrm{Cl}$ noted:

The exercise is useful, as it puts all the people in a room and [makes you] sit next to the person and work with the person. The objective of knowing who to call was a good exercise...we also practiced how to log these incidents to OCTUS and how to properly close the incidents.

The benefits of the scenario exercises were also seen when some of the scenarios did occur during the actual event. Everybody was well-prepared to handle these scenarios as they had practiced the response during the scenario exercises. The Chairman of $\mathrm{Cl}$ elaborated:

Yes, [some of the scenarios occurred]... virus attack, network slowness...but we managed to contain it, because...we had gone through the scenario. All of us knew what to do.

\section{Monitoring the Event}

During the actual event, the $\mathrm{Cl}$ members worked in two shifts so that real-time monitoring and response could take place round the clock. Monitoring of network and the hosting environment were ongoing. Daily summary reports with incident details were submitted. All incidents were logged and updated on OCTUS. Information from OCTUS was projected on screens in the command and operations centre to keep all staff members updated on the situations. The most important function of OCTUS was situation awareness. The Chairman of $\mathrm{Cl}$ elaborated:
We knew where and when each event was going to be. If the projector was faulty we knew it immediately because it is a realtime system. We knew which personnel were sick. We knew if the limousine driver [of a delegate] was involved in an accident...We knew everything through [OCTUS].

The use of the $3 \mathrm{G}$ mobile phones together with OCTUS provided rapid information dissemination among the liaison officers, the Organizing Committee, and the command center so that all information requests and needs were responded to immediately. The use of $3 G$ phones provided richness of media. For example, $3 G$ phones were used to take pictures of incidents or situations that warranted attention and upload this data through OCTUS to alert the command centre. OCTUS also "pushed" information to the $3 \mathrm{G}$ phones, thus updating the liaison officers on any alternations in situations or events, such as changes in meeting venues. The Chairman of $\mathrm{Cl}$ commented:

The OCTUS system has over 40036 phones that were carried by the delegate liaison officers, so everywhere they go, they are able to constantly give us feedback of the happenings at the ground, so the committee can get the latest update of what is happening.

The use of OCTUS and PRS also enabled provision of hospitality services to the delegates as all details of their accommodation and transport had been captured and taken care of. The systems allowed the Singapore government, the private sector, and volunteers to work seamlessly together to ensure the smooth operation of the event.

During the first few days, there were incidents such as slowness in the network at the registration counter due to high volume of printing of registration passes. The $\mathrm{Cl}$ resolved this problem by working closely with the JS to identify the bottleneck and increase the bandwidth of the network. There were also many Helpdesk requests from the delegates. Most of these pertained to the use of the IT equipment as the delegates were not familiar 


\begin{tabular}{|l|l|}
\hline Table 1 - IS Requirements and CI Solutions \\
\hline Requirement & CI Solution (Managerial and IT) \\
\hline Staying Connected & $\begin{array}{l}\text { Partnership with Cisco Systems to provide network infra- } \\
\text { structure. Partnership with Alcatel to provide analog and } \\
\text { digital phones }\end{array}$ \\
\hline IT connectivity & Development of the SES Email System \\
\hline Internal messaging & $\begin{array}{l}\text { Set up to provide telecommunications, postal and courier } \\
\text { service for delegates. The services and equipment were } \\
\text { made available through partnership with Singapore Tele- } \\
\text { communications, Singapore Post, DHL and United Parcel } \\
\text { Service. }\end{array}$ \\
\hline Business center & $\begin{array}{l}\text { Partnership with IDA's Wireless@SG program to provide } \\
\text { wireless access }\end{array}$ \\
\hline Wireless access & $\begin{array}{l}\text { Partnership with local carrier SingTel to provide connectivity } \\
\text { informational services }\end{array}$ \\
\hline Situation Awareness & $\begin{array}{l}\text { OCTUS was specifically designed for this event. Real-time } \\
\text { Real-time event monitoring and } \\
\text { event monitoring took place in shifts round the clock during } \\
\text { the actual event. }\end{array}$ \\
\hline Security at All Times & $\begin{array}{l}\text { Partnership with E-Cop to monitor round-the-clock using } \\
\text { surveillance technology }\end{array}$ \\
\hline Computer security monitoring \\
\hline
\end{tabular}

\begin{tabular}{|c|c|c|}
\hline Planning Phase & Preparation Phase & Execution Phase \\
\hline $\begin{array}{l}\text { Major activities: } \\
\text { - } \text { Bidding to host event } \\
\text { - Setting up the commit- } \\
\text { tees } \\
\text { - } \text { Visiting the Annual } \\
\text { Meetings } \\
\text { - Gathering require- } \\
\text { ments } \\
\text { - Approving } \\
\text { plans/budgets } \\
\text { Key concerns: } \\
\text { - Finding the right com- } \\
\text { mittee members }\end{array}$ & $\begin{array}{l}\text { Major activities: } \\
\text { - Calling tenders } \\
\text { - Managing require- } \\
\text { - } \text { Wents } \\
\text { Vorking with the pri- } \\
\text { - Negotiating with the JS } \\
\text { - } \text { Developing applica- } \\
\text { tions } \\
\text { Key concerns: } \\
\text { - Managing significant } \\
\text { requirements for IT } \\
\text { equipment } \\
\text { - Asset disposal } \\
\text { - Frequently-changing } \\
\text { requirements } \\
\text { Challenges working } \\
\text { with other committees }\end{array}$ & $\begin{array}{l}\text { Major activities: } \\
\text { - Conducting scenario } \\
\text { exercises } \\
\text { - Setting up infrastruc- } \\
\text { ture } \\
\text { - Delivering services } \\
\text { - } \text { Monitoring the event } \\
\text { - Responding to inci- } \\
\text { dents } \\
\text { Key concerns: } \\
\text { - Short amount of time } \\
\text { to set up and tear } \\
\text { down IT infrastructure } \\
\text { - Last-minute changing } \\
\text { requirements } \\
\text { Incidents during the } \\
\text { event }\end{array}$ \\
\hline
\end{tabular}


with the equipment or needed help to get started with their work. After the first few days, the number of incidents and Helpdesk requests decreased.

The three phases and their respective main activities and major concerns are summarized in Figure 2. Additionally, Table 1 shows how the IS requirements were satisfied by the $\mathrm{Cl}$ through partnerships with private and public agencies as well as by developing new IS applications.

\section{Lessons Learnt}

S2006 serves as an exemplar of harnessing IS to coordinate and manage a large-scale event. Valuable lessons can be drawn from this experience. While these lessons are applicable for organizations hosting megascale events, such as sporting competitions (e.g., FIFA World Cup) and political events (e.g., World Economic Forum meetings), some of the lessons may also be useful for other situations that require large-scale communication and coordination, such as crisis management or disaster preparedness and recovery. The lessons are divided into five areas, as described below.

\section{Area 1: Preparedness and Planning}

While planning may be common to large IT projects and planned events, preparedness is critical to ensure that planned events proceed smoothly and unplanned events cause minimal disruptions. Preparedness involves anticipation and response for any eventuality that may happen, e.g., through contingency plans and emergency preparedness. "We aim to be bored" was the motto of the $\mathrm{Cl}$ Chairman. Indeed, the $\mathrm{Cl}$ was as prepared as possible in the circumstances. While S2006 was a planned event, the $\mathrm{Cl}$ was also prepared for any unplanned incidents that may happen during the event. All details and logistics for the event were carefully mapped out. Contingency plans and flow charts were proposed and approved. As noted by the $\mathrm{Cl}$ Chairman, the importance of preparedness cannot be overemphasized.
Scenario exercises were conducted to familiarize all $\mathrm{Cl}$ members with the prescribed procedures and contingency plans. The exercises ranged from table-top efforts to fulltroop exercises. All members of the $\mathrm{Cl}$ participated in the scenario exercises, so that everyone was trained and fully prepared for the range of situations. During the scenario exercises, OCTUS was used by the $\mathrm{Cl}$ and other committee members to log incidents and update the command centre. They were this familiar with how to use the system so that they are not caught off-guard in times of emergencies. People knew how they should respond to different contingencies and who they should call should incidents occur. The communications functions were thus well tested before the actual event. The $\mathrm{Cl}$ anticipated problems in advance and made provisions to resolve these problems. Through this case, we learn various ways of planning to achieve preparedness, i.e., contingency plans and scenario exercises.

Preparedness is also critical for unplanned events such as crises or disasters. Business continuity and disaster recovery starts with planning and preparing for the unexpected. As highlighted in the case, contingency plans and scenario exercises are essential for the smooth operations and use of IS to support large-scale coordination that is required even during crisis management and disaster recovery. Exercises involving crisis simulations are important for organizational and individual learning (Borodzicz and Haperen, 2002). Disaster response exercises can be used to test procedures and technologies and allow personnel to be better prepared (Simmons et al., 2003). For example, New Orleans-based Entergy Corporation was well-prepared for Hurricane Katrina because of its disaster recovery plans and the drills that it conducted (Overby, 2005). The disaster recovery plans were revised and tested once a year and the drills included scenarios such as hurricanes followed by flooding. Planning and preparedness also enables the parties involved to quickly set up the required IT infrastructure. The preparation steps taken for the \$2006 
project serve as an example of the planning and preparedness that is needed to ensure effective large-scale communication and coordination through the use of IS.

\section{Area 2: Use of IS for Situation Awareness}

Situation awareness requires round-theclock real-time monitoring of an event. It involves actively tracking the status of the event so that any exceptional incidents can be quickly detected and resolved. It also includes maintaining control of the event in the absence of incidents. For large-scale events such as S2006, real-time monitoring and situation awareness are critical due to the large number of attendees, the multiple venues, various meetings happening concurrently, and high visibility and security requirements. In the S2006 project, the development and use of OCTUS for situation awareness and event monitoring proved to be crucial to the smooth running of the entire event. It was instrumental in facilitating situation awareness and problem resolution. This was integrated with real-time updates that were sent to the command centre through $3 \mathrm{G}$ mobile phones carried by operational personnel. This allowed the event organizers to be constantly aware of all aspects of what was happening on the ground. Every incident was logged in OCTUS to ensure timely resolution.

While OCTUS was used for the S2006 event monitoring, such a system may also be valuable for situation awareness and incident handling during emergency response or crisis management. Systems with $3 G$ connectivity can be used for large-scale communication, allowing people on the ground to communicate and send information real-time to the control centre, and also for control centre personnel to send information and instructions to people on the ground. In the Gulf oil spill incident, mobile phone software was developed to allow fishermen and emergency workers to easily input information about oil spill events such as dead wildlife or new oil sightings (Kimberly, 2010). Technologies such as tele- presence systems that present live video feeds (McCurdy et al., 2005), telehealth systems (Simmons et al., 2003), and geographic information system coupled with spatial video acquisition (Curtis et al., 2007) can aid in situation awareness during crisis management. Other technologies such as Web 2.0 applications and remote-sensing systems can also be used to facilitate disaster management (Underwood, 2010). Such systems cannot be developed overnight and have to be designed and built in advance as part of emergency preparedness as described in Area 1. From the S2006 project, we see the importance of carefully planning and developing a suitable IS that enables continuous real-time situation awareness and monitoring with adequate training of users.

\section{Area 3: Cultivating Relationships for Communication and Coordination}

Communication and coordination between multiple stakeholders/participants is necessary in any large-scale event, planned or unplanned. IS such as email and video conferencing software are useful for this purpose especially when the parties are geographically separated. Cultivating relationships between the parties is also helpful in promoting effective communication and amicable work arrangements. In the S2006 project, the $\mathrm{Cl}$ had to manage several important relationships for the smooth implementation of the event. These included relationships within the $\mathrm{Cl}$, the rest of IDA, multiple government agencies and subcommittees (refer to Table $\mathrm{A}$ in the Appen$\operatorname{dix} A$ for the list of agencies), the private sector, the volunteers from the public, and relationships with the JS. Within the $\mathrm{Cl}$, the team building efforts allowed members to work closely together towards their objectives. Strong support from IDA senior management also helped the $\mathrm{Cl}$ to work with the rest of the organization, such as in the cooperation with the Wireless@SG initiative. With the cross-communication during the scenario exercises, the $\mathrm{Cl}$ members got to know people from other government agencies in the other sub-committees. 
However, there were many arduous negotiations with the various sub-committees and the JS. Thus, the relationships had to be handled carefully. Particularly, it was challenging to maintain cordial relationships with the JS because of the physical distance and because the JS expected the Singapore government to meet all requirements, including new or changed requirements. Regular group meetings with the JS using video conferencing helped to ensure clear communication and coordination. When the advance party from the JS visited Singapore prior to the event, the face-to-face discussions facilitated negotiations and making compromises in a cordial manner. From the S2006 event, we see the importance of building relationships with various stakeholders, such as clients and external constituents, and even within the organization.

It is also important to cultivate relationships between parties who play different roles in disaster recovery and crisis management. As described in Area 1, disaster recovery plans need to be meticulously prepared including assignment of specific roles to individuals. However, as disasters drills do not happen frequently, the personnel in charge may not meet or see each other regularly. Hence, it is important to organize meetings, scenario exercises, team building activities, or other events to build relationships. For example, a study on crisis management has highlighted the importance of having frequent exercises to provide opportunities for personnel from different organizations (such as government, hospital, military, and Red Cross representatives) to interact and develop relationships (Militello et al., 2007). At times of crisis, the different personnel will then be able to quickly and effectively communicate with one another. Another case study of crisis management also illustrated the importance of developing trustful relationships with stakeholders even during day-to-day activities, to aid in rapid crisis management (Acquier et al., 2008).

\section{Area 4: Vendor Management}

For developing IS for large-scale event management, projects are frequently outsourced and equipment obtained from various suppliers. Vendor management is an essential skill to ensure the success of the project. Typically, such systems are unique and cannot be bought off the shelf. Hence these systems need to be developed by vendors based on specific requirements from the organization.

In the S2006 project, vendor management skills were critical as the $\mathrm{Cl}$ had to work closely with both their vendors as well as partners who sponsored the equipment and services. In terms of managing vendors, the S2006 event was more challenging than typical IS projects because of the tight deadline given for implementation, set-up, and tear-down. The Cl's amicable working relationships with vendors and industry partners ensured that these parties were accommodating when there were unexpected or last-minute changes in requirements. However, the relationships with partners were not always smooth. As some of the partners were also industry competitors, the $\mathrm{Cl}$ had to manage the relationships very carefully, without giving any appearance of favored treatment or unfair advantage towards any particular partner. The $\mathrm{Cl}$ was also constantly looking for synergy with vendors and industry partners to meet the IS requirements. Instead of purchasing all the IT equipment, the $\mathrm{Cl}$ sought partners in the private sector to sponsor some of the equipment. It was a win-win situation for both parties, as the partners were also eager to showcase their technologies. Indeed, the S2006 project indicates that management of vendors is critical to the success of large-scale projects or events and is an important soft skill that cannot be neglected.

Management of vendors and business partners is also vital as part of planning and preparedness for unexpected events. During times of crisis and emergencies, there may be unexpected and urgent IS requirements which could be quickly met through existing partnerships/ relationships with external organizations. Maintaining amicable 
working relationships or even mutual agreements to help one another can prove to be essential during times of crisis. As described in earlier research on Hurricane Katrina (Junglas and Ives, 2007), suppliers could be critical team members in providing essential equipment and services in the fastest time possible.

\section{Area 5: Project Management and Ex- pertise}

Project management skills and expertise are important in managing large-scale events and leveraging IS for communication and coordination. The scale and complexity of the project under study meant that personnel must have relevant experience and possess the related expertise. The $\mathrm{Cl}$ was staffed with experienced personnel having considerable IT expertise in their respective areas. Some of the members had experience in setting up the IT infrastructure for large events such as the World Trade Organization Ministerial Conference. Even though these events were only a fraction of the size of S2006, they provided insights to the remaining $\mathrm{Cl}$ members, allowing them to anticipate problems in advance. The previous experience of the $\mathrm{Cl}$ team also helped them in preparing the tender specifications and working with the vendors.

Diverse project management skills were also essential because of the complexity of this event and the sheer amount of coordination work that was necessary. All team leaders of the $\mathrm{Cl}$ were also project managers of their respective areas of responsibility, e.g., network and IS security. Another key skill required was negotiation capability, which many of the $\mathrm{Cl}$ members were initially unfamiliar with, but developed over time. The $\mathrm{Cl}$ had to negotiate frequently with the JS to manage the requirements from the JS. The $\mathrm{Cl}$ also had to negotiate with the partners from the private sector to meet the changing requirements from the JS. The $\mathrm{Cl}$ team leader in charge of sponsorship and partnership had prior experience with obtaining sponsorships from the private sector, which helped tremendously when negotiat- ing with these companies. The use of project management tools such as a project management information system could be advantageous for individual and project performance (Raymond and Bergeron 2008). However, we saw that in the S2006 case, the late introduction of the tool could limit the potential impact.

This case exemplifies the importance of complementary resources and capabilities. IT expertise is a necessary core competency, but it has to be complemented with other capabilities such as project management and vendor management skills (described in Area 4), and even negotiation skills. In times of using IS to manage and coordinate crises, project management skills are even more important, as decisions often have to be made fast and be quickly executed. This is also highlighted in a case of crisis management in which the Singapore government had to act swiftly in their decisions relating to the use of e-government infrastructure and resources to combat SARS (Pan et al., 2005).

\section{Framework of IS for Large-Scale Event Management}

We summarize the key lessons learnt from this study in a framework of IS for largescale event management (see Figure 3). The framework is divided into three stages, i.e., planning, preparedness, and event management. While the planning and preparedness phases in S2006 correspond to the planning and preparedness stages in the framework respectively, the execution phase in S2006 spans across the preparedness and the event management stages (see Figure 2).

As discussed in Area 1, preparedness is critical in harnessing IS for large-scale communication, coordination, and event management. In order to achieve preparedness, there must be planning done in advance. The main activity during planning is the gathering of requirements. In the case of S2006 as in many other large-scale events, the key requirements for IT were staying 


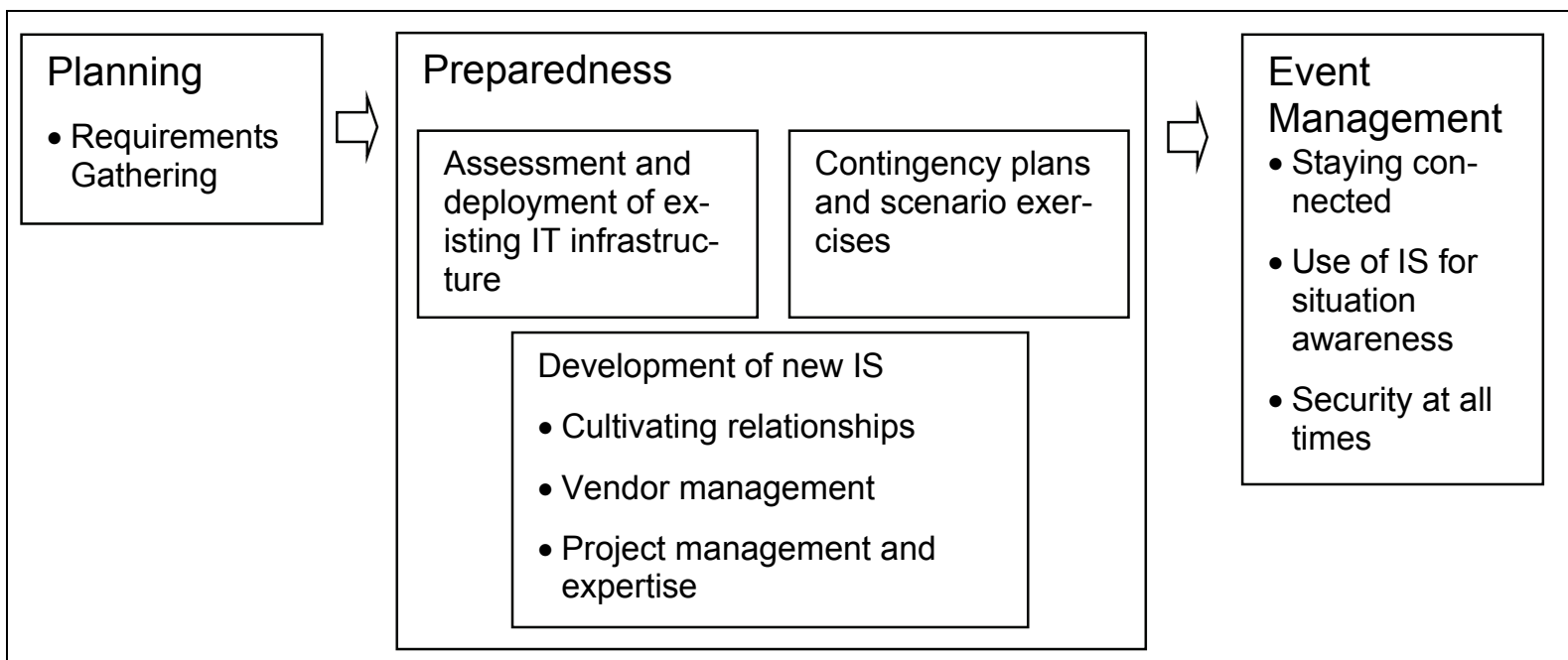

Figure 3 -Framework of IS for Large-Scale Event Management

connected, situation awareness, and security at all times. Budgeting is also necessary to prioritize the requirements according to the available resources.

Preparedness involves assessing existing IT infrastructure for suitability of deployment. For example, in the target case, the existing IT infrastructure of Wireless@SG was deemed to be suitable for the event use. It also involves development of new IS (e.g., OCTUS for S2006) where the existing systems do not meet all the requirements that are gathered during planning. The case also highlights the importance of cultivating relationships for communication and coordination (Area 3), vendor management (Area 4), and project management and expertise (Area 5) for new IS development. Other activities such as scenario exercises and contingency plans are also necessary for preparedness.

With the planning and preparedness described above, this sets the stage for the actual event management. During the actual event, the use of IS for situation awareness greatly assists in the seamless management of the event (Area 2). Other requirements, such as staying connected and security at all times, could be achieved during the actual event based on the planning and preparation that have already taken place.

\section{Discussion and Contributions}

Through this study, we were able to obtain a better understanding of the use of IS for large-scale event management. As described in the literature review, we observed the salience of people characteristics in managing such a large-scale project. Team members required both user knowledge and project expertise to successfully develop and deploy such systems. Our study also confirms the importance of IT project manager skill requirements such as client management, communication and team development. In addition, prior experience in managing such events along with soft skills of vendor management and negotiation skills were found critical for the success of the project and the event.

In terms of IS development processes the literature review identified requirements determination, project management methods, and user participation and training as salient success factors for large-scale projects. Indeed, the project under study exhibited significant challenges in terms of changing and escalating requirements throughout its duration. This study not only highlights this challenge but additionally suggests solutions in terms of negotiation and buffering to alleviate the problem. Another finding from the literature review was the need for project 
management methods to manage such large-scale projects. Further, while user participation and training are found salient for project success in this case as well, this study adds to the literature by identifying specific methods such as scenarios exercises for this purpose and describing how they can be conducted effectively.

Regarding project content, our literature review highlighted issues related to project characteristics, resources, and technology support that must be addressed in largescale projects. Specifically, project complexity and uncertainty created challenges in this study as well. Additionally, our study identified various measures for handling complexity in such projects. First, careful planning, budgeting, and coordination were found effective in reducing uncertainty in the project under study. Second, prior experience assisted the team to anticipate problems in advance and resolve issues swiftly. Further, amicable relationships between different stakeholders were fostered through team-building and scenario exercises where all groups participated. This enabled the entire project team to respond to challenges in a concerted and effective way. For project management technology support, the WBRS system proved useful but the EPMS was introduced too late. Thus, it is important to deploy such systems in a timely manner to leverage their benefits. In terms of handling the paucity of resources, this study suggests novel ways for mitigating this issue through seeking synergy and sponsorships from external parties and vendors.

Last, our literature review had identified issues related to organizational culture, historical background, and environmental conditions that impact IS project success. Specifically, this study adds to the literature by showing how proactive measures by the project leader $(\mathrm{Cl}$ Chairman in this case) could be effective in bridging differences between stakeholders from different organizational cultures and backgrounds. The team building exercises that involved 26 different public agencies and other parties were able to foster cooperation within the $\mathrm{Cl}$.
Further, the environmental context i.e., national objectives in this case, were kept in mind in the planning and development of the project under study. This allowed for considerable synergies to be obtained by leveraging other IT infrastructure initiatives of the government to achieve the goals of this project.

Overall, in terms of lessons learned, while the role of planning and preparedness is not a new lesson, this case highlights the importance of strategies such as contingency plans and scenario exercises. These are not typically seen in management of software projects, but are critical in event management. The need to maintain situation awareness is also necessary and unique to the management of large-scale events, which can be achieved through the use of systems such as OCTUS. Thus, in addition to extending the IS project literature, this study has contributed specifically to IS research in event management, which has seen limited previous work (Rai and Sambamurthy, 2006).

\section{Limitations}

The findings of this study should be interpreted in light of its limitations. While the S2006 case can serve as an exemplar for the use of IS for large-scale events management, caution needs to be exercised in attempting to extend the findings to other contexts and settings. Particularly, we have outlined how some aspects of the study findings could be useful for developing IS for unplanned events in the lessons learnt section. However, there are other unique characteristics of unplanned events in terms of their uncertainty and consequences that warrant separate study. For instance, unplanned events such as natural disasters may require additional design considerations of flexibility for unanticipated requirements, public response management, and the consequences. Thus, further research is needed to examine the extent to which the proposed framework is applicable to develop and deploy IS for managing large-scale unplanned events. 


\section{Conclusion}

This paper describes a case of harnessing IS for the coordination and management of a large-scale event, the $\$ 2006$ project. It outlines the complex requirements and daunting challenges in managing largescale communication and coordination necessary for such an event. The requirements for IS included provision of continuous and seamless connectivity and computer security at all times for participants. For the organizers, systems had to be developed to provide round the clock situation awareness and preparedness. Additional challenges stemmed from managing continuously changing requirements from multiple stakeholders, the non-negotiable deadlines and limited time-frame for IS provision and deployment for the event.

The paper describes how the Committee in charge delivered the IT infrastructure and services for this large-scale international event. It derives several lessons for IT executives responsible for managing such planned events. First, it emphasizes the need for preparedness and planning in exe-

\section{References}

Acquier, A., Gand, S. and Szpirglas, M. (2008). "From Stakeholder to Stakeholder Management in Crisis Episodes: A Case Study in a Public Transportation Company," Journal of Contingencies and Crisis Management, 16(2), pp. 101-114.

Bechor, T., Neumann, S., Zviran, M. and Glezer, C. (2010). "A Contingency Model for Estimating Success of Strategic Information Systems Planning," Information \& Management, 47, pp. 17-29.

Biehl, M. (2007). "Success Factors for Implementing Global Information Systems," Communications of the ACM, 50(1), pp. 53-58.

Borodzicz, E. and Haperen, K. (2002). "Individual and Group Learning in Crisis cuting such projects. Second, it highlights the use of IS to maintain situation awareness. Third, it suggests how relationships can be cultivated among multiple parties to promote effective communication and coordination. Fourth, it emphasizes the importance of vendor management and partnerships with the industry. Fifth, it indicates the salient role of experience and skills (including negotiation) in IT project management for such large-scale projects.

The S2006 experience in using IS is valuable for large-scale projects which involve complex coordination among multiple stakeholders and dynamic requirements under non-negotiable deadlines. The lessons and experiences that were accumulated through the event can be applied for communication and coordination for future large-scale planned events and to some extent for advance preparation for disasters and crisis management. The experiences in managing, developing, and deploying IS could also be useful for other Governments and companies responsible for the organization of mega-scale events.

Simulations," Journal of Contingencies and Crisis Management, 10(3), pp. 139-147.

Chen, R., Sharman, R., Rao, H.R. and Upadhyaya, S.J. (2007). "Emergency Response Coordination and IT support: Contingency and Strategies," The Americas Conferences on Information Systems, Keystone, CO.

Curtis, A., Mills, J.W., Kennedy, B., Fotheringham, S. and McCarthy, T. (2007). "Understanding the Geography of Post-Traumatic Stress: An Academic Justification for Using a Spatial Video Acquisition System in the Response to Hurricane Katrina," Journal of Contingencies and Crisis Management, 15(4), pp. 208-219. 
Dillon, S., Taylor, H. and Rodriguez-Jolly, G. (2011). "The Identification of IT Project Manager Competencies: A Grounded Theory Approach," The Pacific Asia Conference on Information Systems, Paper 54.

Goles, T., White, G.B. and Dietrich, G. (2005). "Dark Screen: An Exercise in Cyber Security," MIS Quarterly Executive, 4(2), pp. 303-318.

Gowan, J.A. and Mathieu, R.G. (2005). "The Importance of Management Practices in IS Project Performance," The Journal of Enterprise Information Management, 18(2), pp. 235-255.

Hart, S. (2010). "How Would You Plug the Gulf Oil Spill? Santa Rosa Social Networking Startup Democrasoft Wants Your Ideas," The Press Democrat, Washington, June 29, 2010.

Hartman, F. and Ashrafi, R.A. (2002). "Project Management in the Information Systems and Information Technologies Industries," Project Management Journal, 33(3), pp. 5-15.

$\mathrm{He}, \mathrm{J}$. and King, W.R. (2008). "Information Systems Development: Implications from a Meta-Analysis," Journal of Management Information Systems, 25(1), pp. 301-331.

Irani, Z., Sharif, A.M. and Love, P.E.D. (2001). "Transforming Failure into Success through Organisational Learning: An Analysis of a Manufacturing Information System," European Journal of Information Systems, 10, pp. 55-66.

Johnson, J., Boucher, K.D., Connors, K. and Robinson, J. (2001). "The Criteria for Success," Software Magazine, 21(1), S3-S11.

Junglas, I. and Ives, B. (2007). "Recovering IT in a Disaster: Lessons from Hurricane Katrina," MIS Quarterly Executive, 6(1), pp. 39-51.
Kautz, K., Hansen, B. and Jacobsen, D. (2004). "The Utilization of Information Systems Development Methodologies in Practice," Journal of Information Technology Cases and Applications, 6(4), pp. 1-20

Kearns, G.S. (2006). "The Effect of Top Management Support of SISP on Strategic IS Management: Insights from the US Electric Power Industry," Omega, 34(3), pp. 263-253.

Kim, C.S. and Peterson, D.K. (2003). "A Comparison of the Perceived Importance of Information Systems Development Strategies by Developers from the United States and Korea," Information Resources Management Journal, 16(1), pp. 1-18.

Kimberly, M. (2010). "West Palm Man's Cellphone Technology Helps Track Oil Spill Woes," Tribune Business News, Washington, May 25, 2010.

Kirsch, L.J. (2000). "Software Project Management: An Integrated Perspective for an Emerging Paradigm, in R. Zmud (ed), Framing the Domains of IT Management: Projecting the Future Through the Past, Pinnaflex Educational Resources, pp. 285-304.

Klein, H.K. and Myers, M.D. (1999). "A Set of Principles for Conducting and Evaluating Interpretive Field Studies in Information Systems," MIS Quarterly, 23(1), pp. 67-93.

Ko, D.-G., Kirsch, L.J. and King, W.R. (2005). "Antecedents of Knowledge Transfer from Consultants to Clients in Enterprise System Implementations," MIS Quarterly, 29(1), pp. 5985.

Kovaleski, D. (2011). "The Big News about Meetings," Association Meetings, April 2011, pp. 14-21.

Lederer, A.L. and Sethi, V. (2003). "The Information Systems Planning Process: Meeting the Challenges of Information Systems Planning," in Gal- 
Information Systems for Large-Scale Event Management: A Case Study / Ng \& Kankanhalli

liers, R.D., and Leidner, D.E. (eds) Strategic Information Management: Challenges and Strategies in Managing Information Systems, third edition, Butterworth-Heinemann.

Lee, M.J. and Back, K.-J. (2005). "A Review of Economic Value Drivers in Convention and Meeting Management Research," International Journal of Contemporary Hospitality Management, 17(5), pp. 409-420.

Levina N. and Su, N. (2008). "Global Multisourcing Strategy: The Emergence of a Supplier Portfolio in Services Offshoring," Decision Sciences, 39(3), pp. 541-570.

Manoj, B.S. and Baker, A.H. (2007). "Communication Challenges in Emergency Response," Communications of the ACM, 50(3), pp. 51-53.

McCurdy, N.J., Griswold, W.G. and Lenert, L.A. (2005). "RealityFlyThrough: Enhancing Situational Awareness for Medical Response to Disasters Using Ubiquitous Video," Proceedings of American Medical Informatics Association, Washington, D. C., 2005, pp. 510-514.

McLeod, L. and MacDonell, S.G. (2011). "Factors that Affect Software Systems Development Project Outcomes: A Survey of Research," ACM Computing Surveys, 43(4), pp. 24-56

Militello, L.G., Patterson, E.S., Bowman, L. and Wears, R. (2007). "Information Flow during Crisis Management: Challenges to Coordination in the Emergency Operations Center," Cognition, Technology and Work, 9(1), pp. 25-31.

Napier, N.P., Keil, M. and Tan, F.B. (2009). "IT Project Managers' Construction of Successful Project Management Practice: A Repertory Grid Investigation," Information Systems Journal, 19(3), pp. 255-282.
Ovaska, P., Rossi, M. and Smolander, K. (2005). "Filtering, Negotiating and Shifting in the Understanding of Information System Requirements," Scandinavian Journal of Information Systems, 17(1), pp. 31-66.

Overby, S. (2005). "Lessons from Hurricane Katrina: It Pays to have a Disaster Recovery Plan in place," ClO, 15 September 2005 Retrieved from http://www.cio.com/article/11931/Les sons_from_Hurricane_Katrina_It_Pa ys_to_Have_a_Disaster_Recovery_ Plan_in_Place on 21 February 2011 .

Pan, S.L., Pan, G. and Devadoss, P.R. (2005). "E-Government Capabilities and Crisis Management: Lessons from Combating SARS in Singapore," MIS Quarterly Executive, 4(4), pp. 385-397.

Pee, L.G., Kankanhalli, A. and Kim, H.-W. (2010). "Knowledge Sharing in Information Systems Development: A Social Interdependence Perspective," Journal of the Association for Information Systems, 11(10), pp. 550-575.

Project Management Institute (2008). A Guide to the Project Management Body of Knowledge, $4^{\text {th }}$ edition, Project Management Institute.

Rai, A. and Sambamurthy, V. (2006). "Editorial notes - The Growth of Interest in Services Management: Opportunities for Information Systems Scholars, Information Systems Research, 17(4), pp. 327-331.

Raymond, L. and Bergeron, F. (2008). "Project Management Information Systems: An Empirical Study of Their Impact on Project Managers and Project Success," International Journal of Project Management, 26(2), pp. 213-220.

Reddy, M.C., Sharoda, A.P., Abraham, J., McNeese, M., DeFlitch, C. and Yen, J. (2009). "Challenges to Effective 
Crisis Management: Using Information and Communication Technologies to Coordinate Emergency Medical Services and Emergency Department Teams, International Journal of Medical Informatics, 78, pp. 259-269.

Ritter, J., Lyons, J.B. and Swindler, S.D. (2007). "Large-Scale Coordination: Developing a Framework to Evaluate Socio-Technical and Collaborative Issues," Cognition, Technology and Work, 9(1), pp. 33-38.

Shone, A. and Parry, B. (2010). Successful Event Management: A Practical Handbook, $3^{\text {rd }}$ edition, Cengage Learning EMEA.

Simmons, S.C., Murphy, T.A., Blanarovich, A., Workman, F.T., Rosenthal, D.A. and Carbone, M. (2003). "Telehealth Technologies and Applications for Terrorism Response: A Report of the 2002 Coastal North Carolina Domestic Preparedness Training Exercise," Journal of the American Medical Informatics Association, 10, pp. 166176.

Skok, W. and Legge, M. (2002). "Evaluating Enterprise Resource Planning (ERP) Systems Using an Interpretive Approach," Knowledge and Process Management, 9(2), pp. 72-82.
The Economic Times (2010). "Mahindra Satyam Driving FIFA World Cup's Software Network," The Economic Times, June 11, 2010 Retrieved from

http://economictimes.indiatimes.com/ articleshow/6037982.cms?prtpage $=1$ on 17 February 2011.

Thomas, J. and Mengel, T. (2008). "Preparing Project Managers to Deal with Complexity - Advanced Project Management Education," International Journal of Project Management, 26, pp. 304-315.

Thomson Reuters (2010). "Thomson Reuters Helps Poison Control Centers and the CDC Monitor Toxic Exposure to Gulf of Mexico Oil Spill," $P R$ Newswire, New York, May 25, 2010.

Underwood, S. (2010). "Improving Disaster Management," Communications of the ACM, 53(2), pp. 18-20.

Walsham, G. (2006). "Doing Interpretive Research," European Journal of Information Systems, 15, pp. 320-330. http://www.weforum.org/reports on 17 February 2011.

Yin, R.K. (2008). Case Study Research: Design and Methods, $4^{\text {th }}$ edition. Thousand Oaks, California: Sage Publications. 


\section{Appendix A: Organization Structure and Roles of Committees}

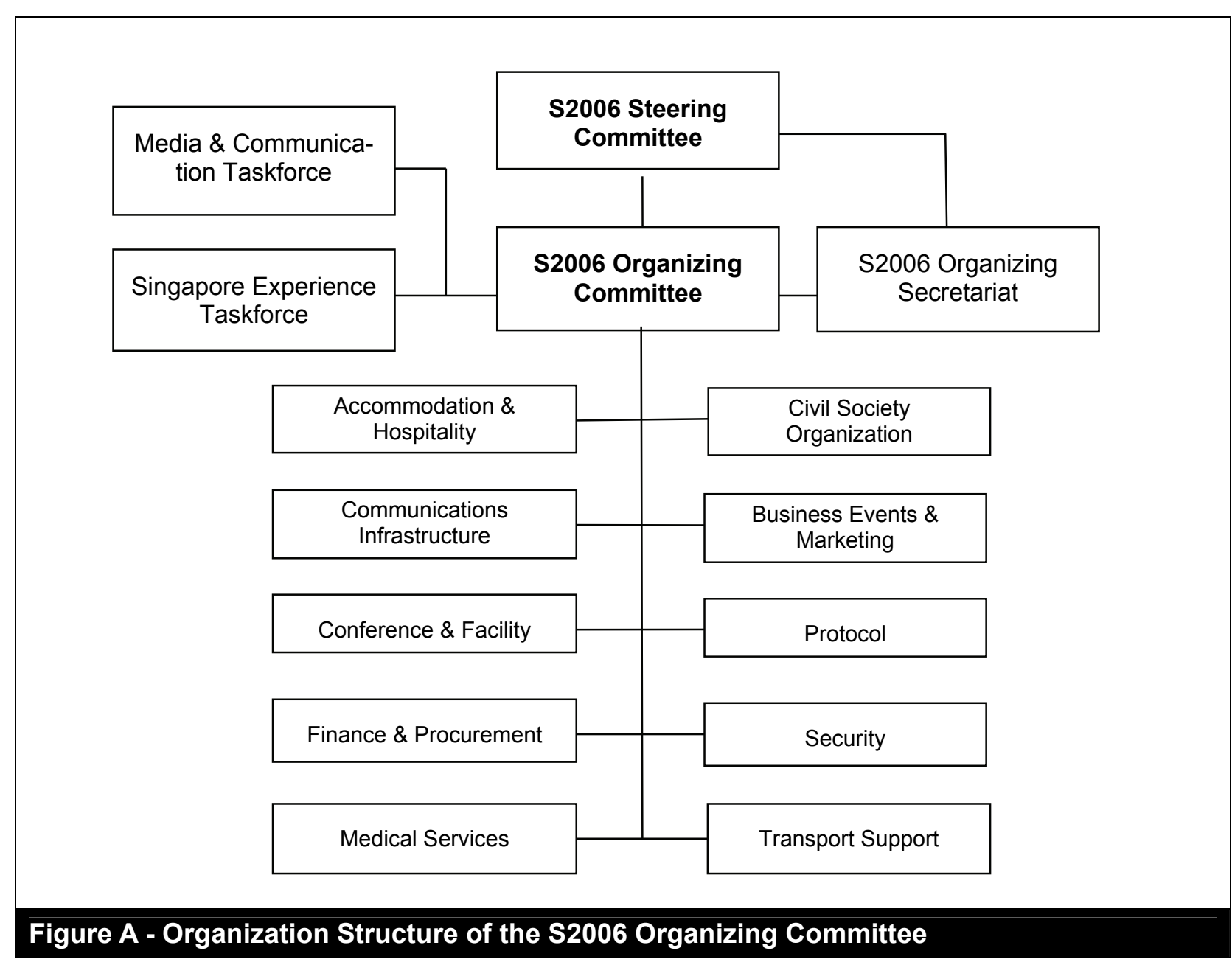

The S2006 Steering Committee was set up to provide directions for the Organizing Committee and consisted of Permanent Secretaries whose agencies were expected to be actively involved in the preparation. It set policies and approved major plans to ensure the successful hosting of the Annual Meetings. The Organizing Committee was in charge of the execution of plans in accordance with the policy framework and directives determined by the Steering Committee. It also identified and acquired the resources required from across the public sector and nationwide for hosting the event.
The other members of the Organizing Committee were the Chairpersons of the ten sub-committees (see Figure A). The Organizing Secretariat provided support to the ongoing activities of the Steering and Organizing Committees. Besides linking up with JS, the Organizing Secretariat was also the key contact point for co-ordination of issues involving two or more sub-committees to ensure that planning initiatives are wellcoordinated. The roles of the ten subcommittees, as well as the lead and supporting agencies, are listed in Table A. 


\begin{tabular}{|c|c|c|}
\hline Committee & Role & Agencies $^{2}$ \\
\hline $\begin{array}{l}\text { Media \& Communi- } \\
\text { cation Taskforce }\end{array}$ & $\begin{array}{l}\text { It oversees media and communication activities to promote } \\
\text { Singapore and S2006. Its areas of responsibility are Media } \\
\text { Management, Publicity, Collateral and Crisis Communica- } \\
\text { tions. }\end{array}$ & MICA \\
\hline $\begin{array}{l}\text { Singapore Experi- } \\
\text { ence Taskforce }\end{array}$ & $\begin{array}{l}\text { It creates a uniquely Singapore experience for all interna- } \\
\text { tional visitors at all touch points. It also oversees the vari- } \\
\text { ous programs to promote Singapore as a vibrant tourist } \\
\text { destination and a hospitable nation. }\end{array}$ & STB \\
\hline $\begin{array}{l}\text { Accommodation and } \\
\text { Hospitality }\end{array}$ & $\begin{array}{l}\text { It manages the accommodation needs and organizes the } \\
\text { social events for the meeting participants. }\end{array}$ & STB \\
\hline $\begin{array}{l}\text { Business Events and } \\
\text { Marketing }\end{array}$ & $\begin{array}{l}\text { It works with the public and private sector partners to de- } \\
\text { velop programs and platforms to facilitate business and } \\
\text { networking opportunities for companies, and profiles Sin- } \\
\text { gapore as an international financial centre. It also over- } \\
\text { sees content development, marketing programs and other } \\
\text { lead-up activities for the various seminars. }\end{array}$ & $\begin{array}{l}\text { MAS, MICA, EDB, } \\
\text { IES, MOF, MTI, STB }\end{array}$ \\
\hline $\begin{array}{l}\text { Civil Society Organi- } \\
\text { zation }\end{array}$ & $\begin{array}{l}\text { It works closely with the JS on all matters concerning } \\
\text { CSO's participation in the Annual Meetings. }\end{array}$ & $\begin{array}{l}\text { MFA, MICA, ICA, } \\
\text { SPF }\end{array}$ \\
\hline $\begin{array}{l}\text { Communications } \\
\text { Infrastructure }\end{array}$ & $\begin{array}{l}\text { It oversees, manages and coordinates the IS requirements } \\
\text { for the Annual Meetings. }\end{array}$ & IDA \\
\hline $\begin{array}{l}\text { Conference and Fa- } \\
\text { cility }\end{array}$ & $\begin{array}{l}\text { It oversees, manages and coordinates arrangements to } \\
\text { ensure that the conference venue facilities meet all the } \\
\text { requirements of the JS. It also implements and manages } \\
\text { the conference program together with the JS. }\end{array}$ & $\begin{array}{l}\text { MOF, MAS, } \\
\text { MINDEF URA, } \\
\text { EMA, BCA, HDB, } \\
\text { NEA, STB, } \\
\text { MINDEF, NParks }\end{array}$ \\
\hline $\begin{array}{l}\text { Finance and Pro- } \\
\text { curement }\end{array}$ & $\begin{array}{l}\text { It oversees and manages the approved overall budget, } \\
\text { draws up the operational guidance and monitors the finan- } \\
\text { cial procedures. }\end{array}$ & MOF, MAS, PSD \\
\hline Medical Services & $\begin{array}{l}\text { It advises the Planning Committee on medical and health } \\
\text { matters. }\end{array}$ & MOH, SCDF \\
\hline Protocol & $\begin{array}{l}\text { It oversees and manages all matters relating to protocol } \\
\text { and ensure that all delegates are accorded appropriate } \\
\text { level of protocol. }\end{array}$ & MFA \\
\hline Security & $\begin{array}{l}\text { It oversees, manages and coordinates with relevant agen- } \\
\text { cies to meet the security requirements of the Annual Meet- } \\
\text { ings. }\end{array}$ & $\begin{array}{l}\text { SPF, HSA, MHA, } \\
\text { MINDEF, NEA, } \\
\text { PUB, SCDF, ICA }\end{array}$ \\
\hline Transport Support & $\begin{array}{l}\text { It oversees and makes transport arrangement for the An- } \\
\text { nual Meetings. }\end{array}$ & $\begin{array}{l}\text { MINDEF, LTA, } \\
\text { CAAS }\end{array}$ \\
\hline
\end{tabular}

\footnotetext{
${ }^{2}$ Lead agencies are in bold.

${ }^{3}$ This paper is based on the work of the Communications Infrastructure sub-committee $(\mathrm{Cl})$.
} 
Information Systems for Large-Scale Event Management: A Case Study / Ng \& Kankanhalli

$\begin{array}{ll}\text { Legend: } & \\ \text { BCA } & \text { - Building and Construction Authority } \\ \text { CAAS } & \text { - Civil Aviation Authority of Singapore } \\ \text { EDB } & \text { - Economic Development Board } \\ \text { EMA } & \text { - Energy Market Authority } \\ \text { HDB } & \text { - Housing and Development Board } \\ \text { HSA } & \text { - Health Science Authority } \\ \text { ICA } & \text { - Immigration and Checkpoints Authority } \\ \text { IDA } & \text { - Infocomm Development Authority of } \\ & \text { Singapore } \\ \text { IES } & \text { - International Enterprise Singapore } \\ \text { LTA } & \text { - Land Transport Authority } \\ \text { MAS } & \text { - Monetary Authority of Singapore } \\ \text { MFA } & \text { - Ministry of Foreign Affairs } \\ \text { MHA } & \text { - Ministry of Home Affairs }\end{array}$

\section{Appendix B: Interview Protocol}

The following is an overview of the interview questions used by the researchers. The actual interview questions may vary slightly according to the interviewee's role and his/her responses.

\section{A. General}

A1. Describe your roles and responsibilities in the $\mathrm{Cl}$.

A2. How long were you in the $\mathrm{Cl}$ ?

B. Planning Phase

B1. Describe the planning process that was undertaken for the Cl's work (for your involvement). What needs to be done? How long was this phase? What are the major milestones? Were they met on time?

B2. Who were the people involved in the planning process? Were external parties (e.g. other government agencies, consultants, overseas counterparts) involved? How were they involved?

B3. How was the senior management involved in the planning process? Who were the senior management involved?

B4. Describe the process that was involved in obtaining funding for the Cl's work. Were the deliverables accomplished within budget? Why and why not?

B5. Did anything unusual or unexpected happen during the planning phase? How did you resolve it?

B6. What were the constraints and challenges experienced during this phase

$\begin{array}{ll}\text { MICA } & \text { - Ministry of Information, } \\ \text { MINDEF } & \text { Communication \& the Arts } \\ \text { MOF } & \text { - Ministry of Defence } \\ \text { MOH } & \text { - Ministry of Finance } \\ \text { MTI } & \text { - Ministry of Tradth } \\ \text { NEA } & \text { - National Environmental Agency } \\ \text { NPARKS } & \text { - National Parks } \\ \text { PSD } & \text { - Public Service Division } \\ \text { PUB } & \text { - Public Utilities Board } \\ \text { SCDF } & \text { - Singapore Civil Defence Force } \\ \text { SPF } & \text { - Singapore Police Force } \\ \text { STB } & \text { - Singapore Tourism Board } \\ \text { URA } & \text { - Urban Development Authority }\end{array}$

and how were these surmounted?

\section{Preparation Phase}

C1. Describe the preparation process that was undertaken for the Cl's work (for your involvement). What needed to be done? How long was this phase? What are the major milestones? Were they met on time?

C2. Who were the people involved in the preparation process? Were external parties (e.g. other government agencies, consultants, overseas counterparts) involved? How were they involved?

C3. How was the coordination and communication preformed with the involved parties? What were the channels? Did you use any communication/collaboration tools and technologies?

C4. How was the senior management involved in the preparation process? Who were the senior management involved?

C5. Was any part of the preparation outsourced? What were the reasons for outsourcing? Describe the outsourcing process. Were there any issues/challenges?

C6. What were the responsibilities of the vendors? How did the $\mathrm{Cl}$ ensure that the vendors are delivering the products/services as expected? How closely did you work with the vendors?

C7. Did anything unusual or unexpected 
happen during the preparation phase? How did you resolve it?

C8. Were there any previous experiences with preparation for similar events such as S2006? How did the presence/absence of this prior experience help or impair the planning and preparation of the $\mathrm{Cl}$ for S2006? In the case where there was an absence of prior experience, how was this addressed?

c9. What were the constraints and challenges experienced during this phase and how were these surmounted?

C10. What were the key factors/issues that you think contributed to the successful completion of planning and preparation for the $\mathrm{Cl}$ ? How were these demonstrated?

C11. Who are the "users"? Where do the user requirements come from? How were they satisfied?

\section{Information Technology}

D1. Describe the main highlights of the IT used for S2006.

D2. What were the applications that were developed for S2006? What IT platform were they built on? Describe the development process.

D3. Were there any principles and guidelines that need to be adhered to in the development of the S2006 applications? What are these?

D4. What was the funding model used for the IT? What were the reasons for this model?

D5. One of the keywords in the press release is the "seamless" technology experience? How did this idea come about? What does this mean? How did the $\mathrm{Cl}$ deliver such a seamless experience?

\section{E. Execution Phase}

E1. Describe the execution phase and your involvement. What needed to be done? How long was this phase? What are the major milestones? Were they met on time?
E2. What was your role and responsibility during the actual event?

E3. What were the logistics arrangement (e.g. set-up of physical infrastructure, ensure sponsors bring in the equipment) that took place in preparation for S2006? Describe the process of these arrangements.

E4. Did the $\mathrm{Cl}$ have to conduct any training? What was the training for? What was the target audience? How did you think the training went?

E5. What kind of event coordination and monitoring needed to be done by the $\mathrm{Cl}$ ?

E6. What were the constraints and challenges experienced during the event and how were these surmounted?

E7. Any unexpected hiccups during the event and how was that resolved?

\section{F. After $\$ 2006$}

F1. What needed to be done after the completion of the event? How did it work out?

F2. Was there any feedback mechanism in place to evaluate how the event went?

F3. On hindsight, was there anything that could be done differently during the three phases?

F4. What were the key factors/issues that contributed to the success (or the lack of it) of your team's work? How were these demonstrated?

F5. What do you think are important resources that enabled the $\mathrm{Cl}$ to support this event?

F6. What do you think are important capabilities that enabled the $\mathrm{Cl}$ to support this event?

F7. What are the major lessons learnt through this event?

F8. What advice would you give to other organizations that have to support similar events? 
Information Systems for Large-Scale Event Management: A Case Study / Ng \& Kankanhalli

\begin{abstract}
About the Authors
Dr. Atreyi Kankanhalli is Associate Professor in the Dept. of Information Systems at the National University of Singapore (NUS). She serves as the Coordinator of the Service Systems Innovation Research Laboratory at NUS.

Dr. Kankanhalli conducts research in the areas of knowledge management, IT innovation adoption and change management, and IT-enabled innovation in service sectors (e.g., Government, Healthcare) with a range of organizations sponsored by government and industry grants. Her work has appeared in
\end{abstract}

leading journals including MIS Quarterly, Information Systems Research, and Journal of Management Information Systems. Dr. Kankanhalli serves (or has served) on the editorial boards of MIS Quarterly, Information Systems Research, and IEEE Transactions on Engineering Management. She is a recipient of the IBM Faculty Award and the IBM Smarter Planet Industry Skills Innovation Award among others. She has been listed among the leading IS researchers globally. 